the College could collect information concerning the occasions when this particular exemption is used; members are asked to forward such information to the Registrar.

(g) The implications for recording discussions with carers need consideration.

(h) Experience will show whether some GPs may not consult with the previously involved psychiatrist before giving the patient access to psychiatric correspondence.

(i) Full consideration needs to be given to the fact that after the patient's death any person with a legal claim against the estate (such as a person pursuing a claim against the patient in the case of an accident) would have the right of access to the health records. (j) It is not clear that proper consideration has been given to the potentially great amount of time involved for doctors in sifting/editing records for compliance with the Act and in explaining records to patients. Members are encouraged to monitor carefully this work load.

These guidelines were produced by $\mathrm{Dr}$ R. Jones, Secretary of the Public Policy Committee. They are based on a document prepared by Dr Richard Williams, for the Child and Adolescent Psychiatry Specialist Section's Newsletter. The original version is available from the College.

Approved by the Executive and Finance Committee November 1991

\title{
The profession of adult psychotherapist in the NHS
}

\section{Psychotherapy specialist section executive committee}

\section{Introduction}

Adult psychotherapy services in the NHS vary widely across the country. Some districts provide a full service but many have no specialist psychotherapy services or only minimal resources.

Increasing demands for treatment are not being met, with long waiting lists a universal problem. This is of relevance with the orientation towards a consumer led service following the Health Service reforms. The demand cannot be met by the efforts of interested general psychiatrists alone. There has been a gradual expansion of the number of consultant psychotherapists, but little expansion of clinical teams to work with them. If psychotherapy services are to meet requirements they will need to be augmented by an increasing use of non-medical practitioners. If each of the 208 Health Districts in England and Wales is to have a psychotherapy service it will be necessary for the numbers of nonmedical practitioners to be expanded to provide trained and experienced psychotherapy practitioners who will staff the service under the direction of the consultant psychotherapist. A small number (about 20) of posts have been designated in adult psychotherapy on an ad hoc basis by the Department of Health and pay and conditions are often based on the child psychotherapists' scale.

The Working Party of the Psychotherapy Section of the College in its discussion document 'The Future of Psychotherapy Services', has recommended that each Health District should have a small team of psychotherapists responsible for the provision of clinical services, consultation, supervision and teaching. A consultant psychotherapist or consultant psychiatrist with special responsibility for psychotherapy is envisaged as a senior member of the team, so that issues of medical responsibility can be addressed appropriately, liaison with consultants in other medical specialties developed and the training of junior psychiatrists, in line with the College's requirements, met. Such a team will also include professionals from other disciplines including psychology, social work and nurses trained in psychotherapy. The adult psychotherapist could make an important contribution to the work of the District team.

The document proposes (following Cawley) that non-medical psychotherapists might be involved at three different levels of clinical function; the basic level would be equivalent to a counsellor with a preliminary training in psychotherapy. The intermediate level would be a practitioner from an existing health care profession who has specialised in psychotherapy, having taken a minimum of a two year part-time course. The third level would be the specialist psychotherapist with an extensive training. It is at this level of specialist psychotherapy that the organisation of a new profession for non-medical practitioners could be advantageous for mental health services as a whole.

The new profession should include both practitioners trained in psychodynamic methods and cognitive behavioural approaches. 


\section{Implications of a new profession}

The establishment of the new profession of nonmedical psychotherapist and the development of in-service training with nationally agreed standards would enable a high standard of training and practice to be fostered throughout the health service.

Developments in the UKSCP (former Rugby Conference) and elsewhere make clear that diverse trainings and organisations in psychotherapy are proliferating. This has the potential for much fruitful development, but also for problems over methods and standards and a risk of psychotherapy becoming separated from the NHS and psychiatric services. A strong NHS career structure with in-service training would safeguard psychotherapy within the NHS and promote good standards for psychotherapy outside the Health Service. These standards would assist the purchasers of psychotherapy in the internal market by defining the quality of the service that should be provided.

Well qualified psychotherapists, who are not members of a core profession may not necessarily have appropriate experience of working in institutions or have too specialised experience to be suitable for senior posts without further training.

Psychotherapy is particularly well suited to a multidisciplinary approach and this will commonly be the basis for most future services.

\section{Child psychotherapy: a parallel}

The child psychotherapists provide an example of the development of a new profession and of a model that could be suitable for the adult psychotherapist.

A career structure for child psychotherapy was established in 1975 by negotiation with the DHSS. This moved an existing professional group from funding by various bodies to funding by Health. This proved successful in the development of services for children and adolescents. An important aspect of the negotiation with the DHSS was the sponsorship by child psychiatrists who gave strong support to the development of the child psychotherapy profession.

The professional grades for child psychotherapy are based on those for clinical psychology. Child psychotherapists begin clinical work while in training grade posts as part of in-service training. On qualification they are employed at basic grade before moving to senior grade on gaining more experience. The principal child psychotherapist has administrative responsibility for a number of senior child psychotherapists and may be in charge of a district service. The most senior level on the scale is that of Top Grade Child Psychotherapist.

It is likely that child psychotherapists would be interested parties in the new profession and because of their closely relevant experience they would be valuable members of any multidisciplinary working party set up to consider the new profession.

\section{Psychotherapy and the health care professions}

The relationship between a potentially separate psychotherapy profession and the existing caring professions is complex. It is important that the development of specialist psychotherapy should not discourage other colleagues from continuing to practise psychotherapy within their existing professions and jobs. The specialist psychotherapist should have an important role in supporting the use of psychotherapy within other professions by dint of clinical attachments, teaching and supervision.

Some individuals will want to move into more highly specialised psychotherapeutic work. One of the motivations for this may be the difficulty of continuing to practise psychotherapy at a specialist level while becoming more senior in their own profession. By contrast psychiatrists have their recognised specialty of psychotherapy. Many from other professions such as psychology and social work will have already completed psychotherapy trainings and may feel that their professional identity is closer to that of a psychotherapist than to their original profession. Equally there will be others, who, despite expertise in psychotherapy do not wish to give up the broader identity of their original progression.

\section{Recruitment and entry qualifications}

\section{Core professions}

For psychotherapy the core professions are usually taken to be psychiatry, clinical psychology, and social work. To these might be added those other main professions who work in the mental health field, nursing, occupational therapy and speech therapy. There are great differences in the basic training and educational background of all these disciplines but subject to personal ability and any agreed criteria, personnel could be recruited from any of these. For some (e.g. psychologists) it could be relatively easy to remain in the prior discipline and work as a highly trained psychotherapist. For others (e.g. nurses, occupational therapists) it could be exceedingly difficult. In all these disciplines we believe that there are potential recruits and some other people already highly trained, who would wish to develop the proposed new profession of adult psychotherapist. The advantage of recruiting from the core professions springs from the accumulated prior clinical experience, familiarity with the health service, existing codes of ethics and professional practice. 


\section{Non-core professions}

There is long and ample experience from child psychotherapy showing that some of the most gifted and dedicated therapists come to the work from backgrounds as diverse as anthropology, school teaching, the church and the humanities in general. Naturally a longer training is likely to be involved for such people but it could be wasteful to exclude them. For those without a mental health care background there should be an obligatory requirement for study of the phenomena of major mental disorder, its recognition and treatment of the common presentation of physical illness with alteration of psychological function.

\section{Graduate or non-graduate entry}

For a new profession, concerned with its credentials, graduate entry could be a prudent requirement. It could, however, be a counter-productive obstacle to excellent recruits from those core professions where a degree is not now required and must often be rather irrelevant, except as one possible index of general ability and cultivation. Graduate entry could also be a wasteful requirement for mature recruits whose breadth and depth of life experience are a rich resource for this work and for whom it could be a waste of precious remaining years to delay training while getting a degree.

One sensible compromise would be to give preference to graduates or those with equivalent professional qualifications but that this should not be a rigid criterion at any time. Selection committees should then exercise their discretion to accept gifted trainees.

A future possibility would be that psychotherapy training could, as in some countries, become an academic degree course (somewhat as is currently proposed and hotly debated in nursing, physiotherapy etc).

\section{The status of existing trainings}

Currently there are numerous trainings in psychotherapy open to non-medicals. Some of these are of a very high standard (e.g. in psychoanalysis, analytical psychotherapy, analytical group therapy, family therapy, etc) and these trainings qualify people for highly skilled independent work and as teachers in their specialty. Members of these professions will be important as teachers and supervisors for the NHS profession. However their grading and pay will require discussion. Without appropriate training in the range of work now expected of a senior registrar in psychotherapy and without substantial experience of work in the NHS, they will not be qualified for the most senior posts in the new NHS specialty. Such "topping up" training should be readily available to enable suitable candidates to become qualified without reduplicating a long training in areas where they are already expert.

\section{Child psychotherapists}

There may be a significant number of experienced child psychotherapists who wish to qualify in adult psychotherapy and further training should be available to enable them to do this. Eventually adult psychotherapists may wish to qualify in child psychotherapy. Cross-fertilisation and mutual goodwill between the professions of child and adult psychotherapy will be of value in strengthening them both.

\section{The career structure}

A career structure for non-medical psychotherapists would have advantages if it were broad and flexible to allow for different levels of experience, training and clinical functioning. Psychotherapists should be able to remain in career posts at various points on the scale.

This would allow for those psychotherapists whose main function would be in providing treatment as well as those senior therapists who would be more involved in supervision, teaching and management.

\section{The training and "practitioner" grades}

These grades would have several incremental points with periodic assessment. Entry would be through basic training or at a level appropriate to other training and experience in the case of individuals transferring from other professions.

Some members of core professions may wish to remain within their professions and include some psychotherapy within their professional work. Others may wish, on the basis of further training, to commit more of their time to psychotherapy and change their profession to become psychotherapists in the practitioner grade.

Others without a core profession but with psychotherapy training will also form part of the practitioner grade.

\section{The "Senior Specialist"grade}

This would be for practitioners with considerable further specialist psychotherapy training. They will be experienced to undertake senior administrative supervision and training roles.

At first this grade would be filled by people from the core professions with specialist psychotherapy training. The grade could also be open to non-core professionals with sufficient special expertise and experience and who have had suitable additional 
"topping up" training as mentioned under "the status of the existing trainings' above. Eventually the senior specialist grade will usually be filled by promotion from lower grades in the psychotherapists scale.

Some recruits to adult psychotherapy, from the core professions, will be people who will enter the specialist professional training at levels comparable to Registrar or Senior Registrar and they might qualify on completion of 4 year training to the senior specialist grade.

Criteria for the establishment of each individual psychotherapist's position on these scales will be determined primarily by the level of their background education and psychotherapy training. The range of experience and skills, decision making, creativity and training activities will also be important parameters to consider in deciding the position on the pay scale.

\section{Multidisciplinary Working Party Working party agenda}

We suggest that the issues sketched out in this paper could be explored more thoroughly if a multidisciplinary Working Party were to be set up by the $\mathrm{DoH}$, in consultation with the Royal College of Psychiatrists, with the aim of establishing the new profession on a sound basis.

The working party would need to consider the following questions:

1. the role of a new profession in the development of psychotherapy as a clinical service within psychiatry

2. its relationship to psychiatry and the other core professions

3. entry qualifications

4. training requirements

5. career structure

6. salary scales.

If the College were to be involved in encouraging this development, it could be influential in promoting high standards of training and practice and in encouraging the new profession to maintain close links with psychiatry.

\section{Working Party membership}

It is hoped that an appropriate small group of members will be able to cover the main areas of professional experience and concern, and that it will not be necessary to recruit representatives of all the numerous separate interested parties. As a basis, we suggest tentatively that there should be at least the following:

1. at least one DoH nominee for essential expertise from the employing authority

2. a senior nominee from the General Psychiatry Section of the Royal College of Psychiatrists

3. a consultant psychotherapist nominee from the Psychotherapy Section of the Royal College of Psychiatrists

4. nominees from the professions of Clinical Psychology and Social Work, if these are not already covered by the following nominees

5. a nominee from a regional centre-providing experience of the successful development of inter-disciplinary training in psychotherapy at a distance from London. The South Trent Training Scheme in Dynamic Psychotherapy would be appropriate as it has on its staff four adult psychotherapists. The best placed person might be Dr Bernard Ratigan from Nottingham, the only top grade adult psychotherapist in the country

6. a nominee from the Association of Child Psychotherapists - bringing the current experience of this existing (non-medical) psychotherapy profession in the NHS; also, an important interested party since child psychotherapists work with adults too.

Dr N. O. TEMPLE

Chairman, Psychotherapy Specialist Section

Approved by Council

June 1991 